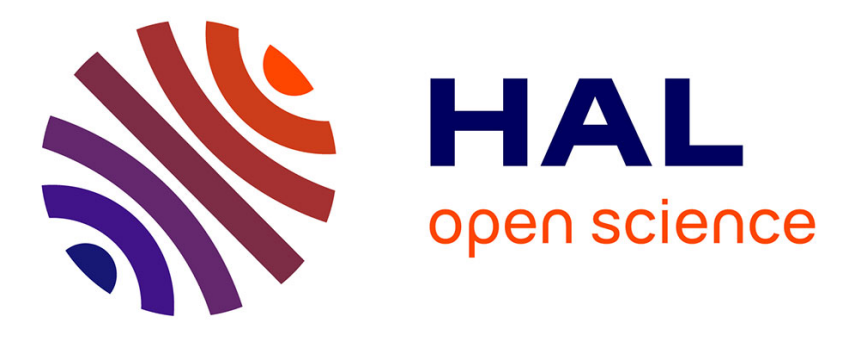

\title{
Rheology of magnetic fiber suspensions
}

\author{
Pavel Kuzhir, Georges Bossis, Alain Meunier, Modesto Lopez-Lopez, Ana \\ Gomez-Ramirez
}

\section{To cite this version:}

Pavel Kuzhir, Georges Bossis, Alain Meunier, Modesto Lopez-Lopez, Ana Gomez-Ramirez. Rheology of magnetic fiber suspensions. 12th international conference on electrorheological fluids and magnetorheological suspension, Aug 2010, Philadelpia, United States. hal-00857158

\section{HAL Id: hal-00857158 https://hal.science/hal-00857158}

Submitted on 2 Sep 2013

HAL is a multi-disciplinary open access archive for the deposit and dissemination of scientific research documents, whether they are published or not. The documents may come from teaching and research institutions in France or abroad, or from public or private research centers.
L'archive ouverte pluridisciplinaire HAL, est destinée au dépôt et à la diffusion de documents scientifiques de niveau recherche, publiés ou non, émanant des établissements d'enseignement et de recherche français ou étrangers, des laboratoires publics ou privés. 

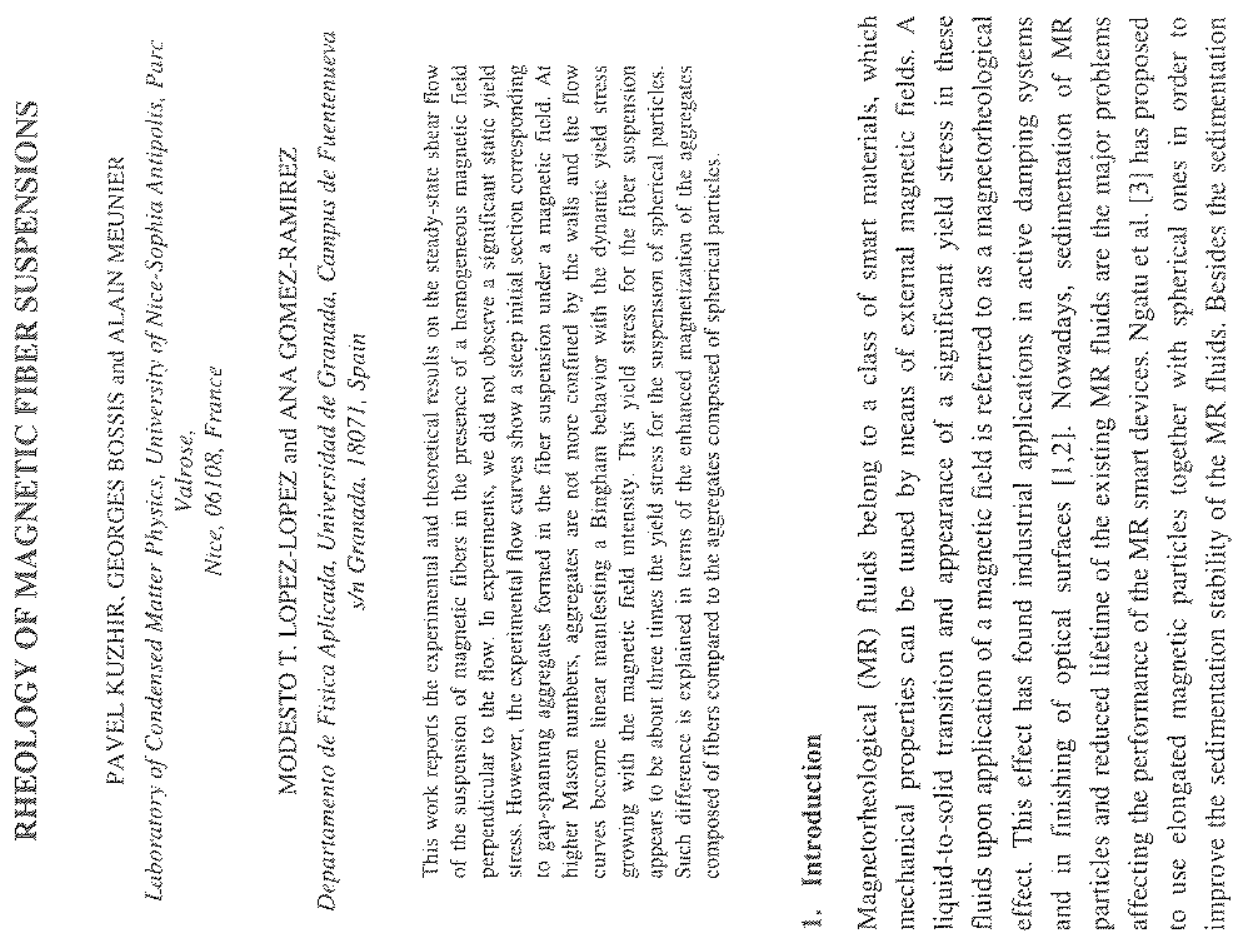

\section{४}

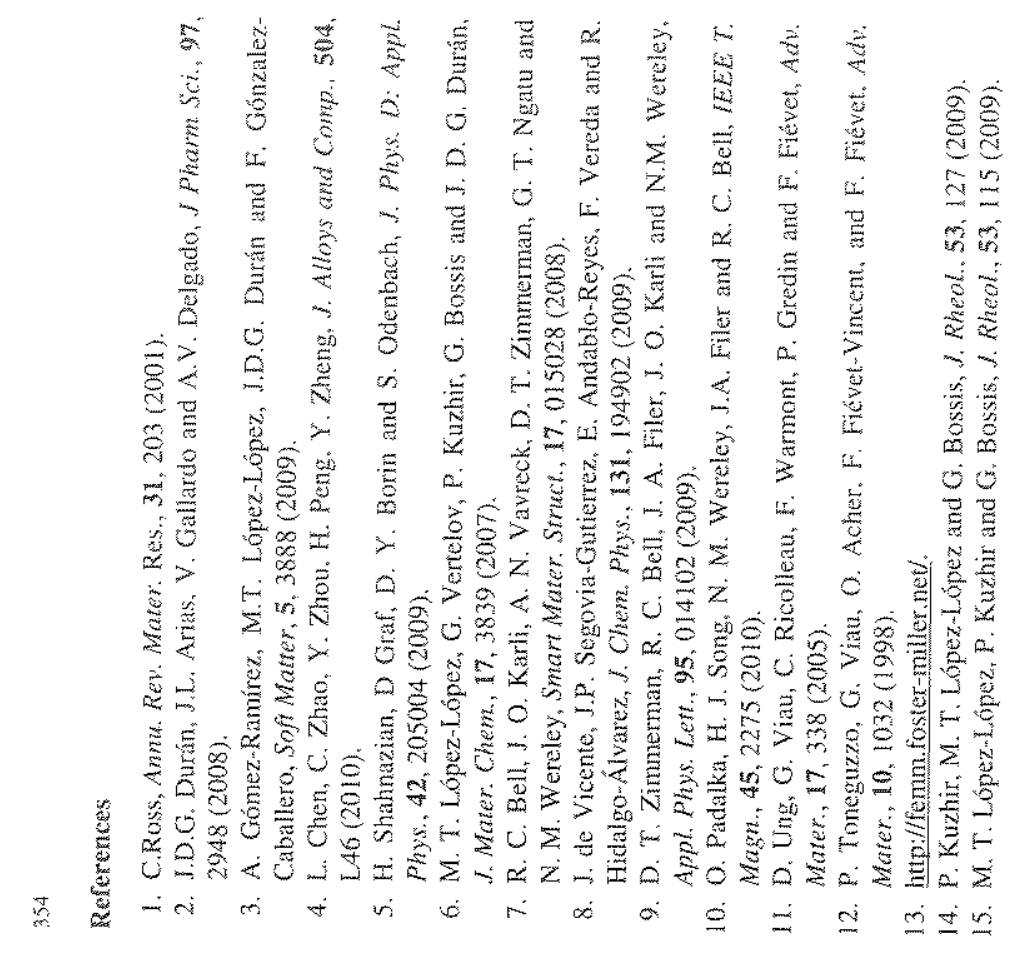


点

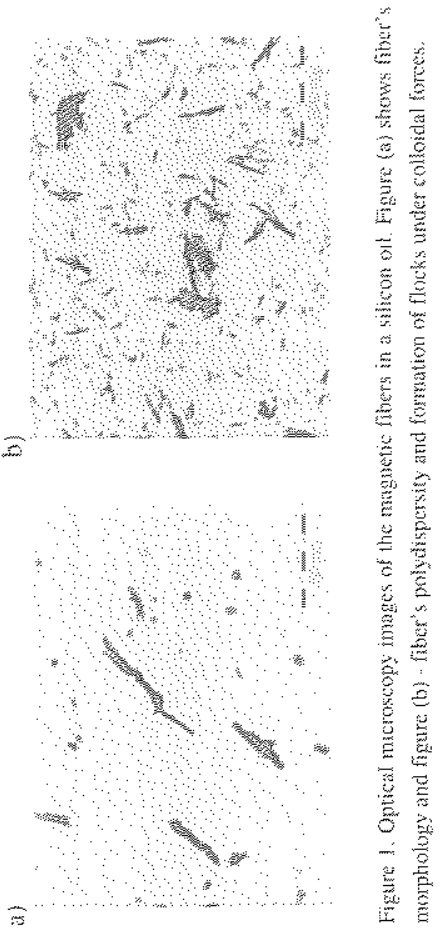

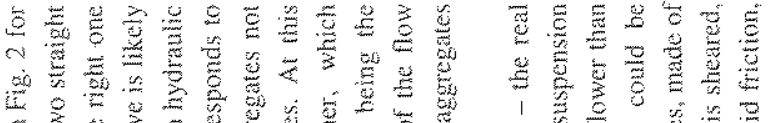

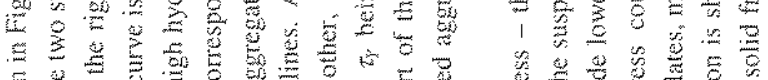

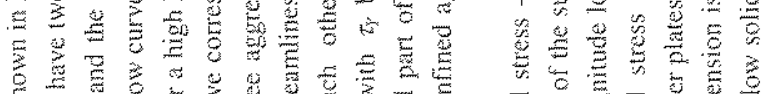

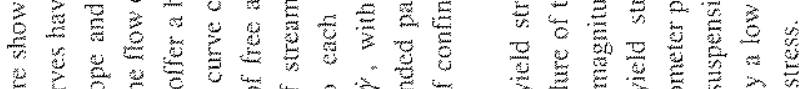

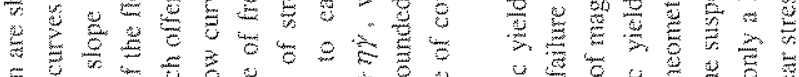

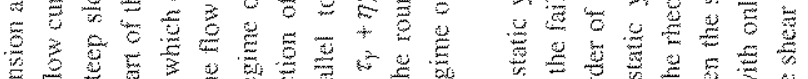

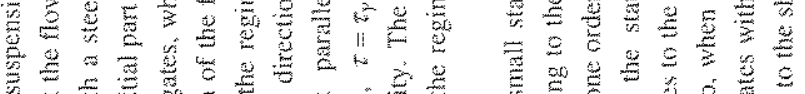

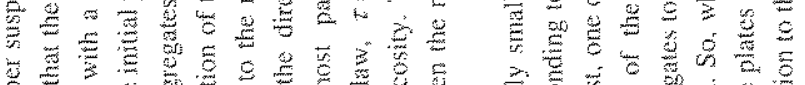

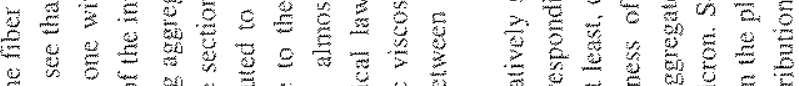

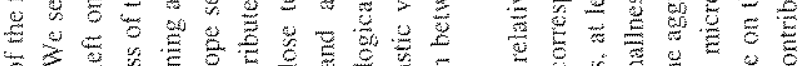

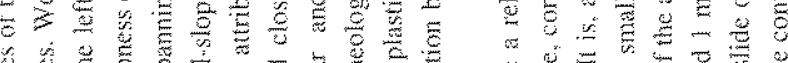

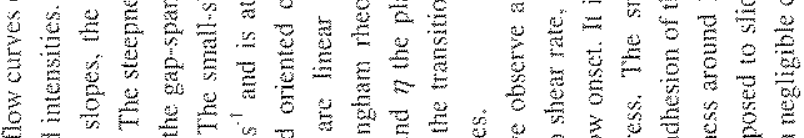

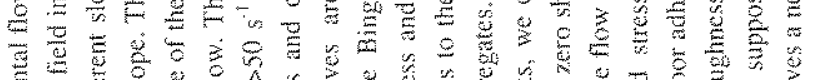

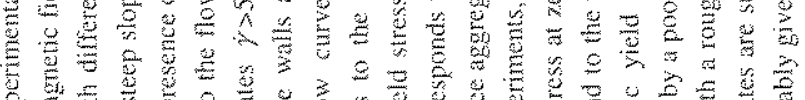

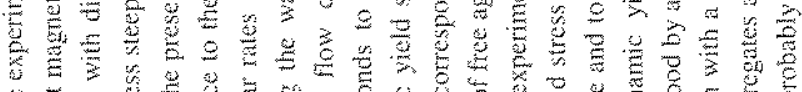

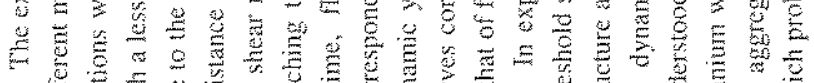

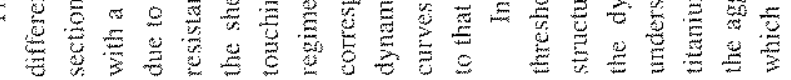

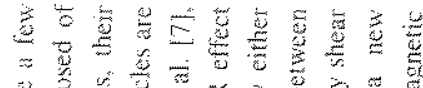

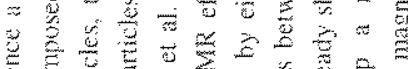

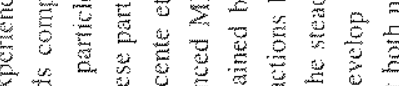

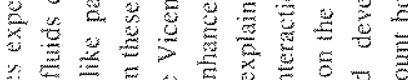

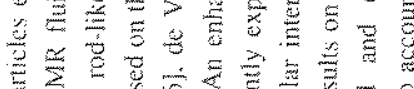

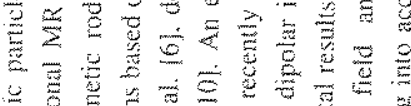

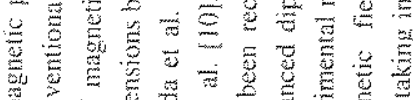

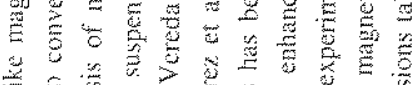

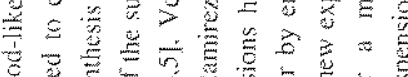

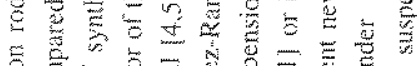

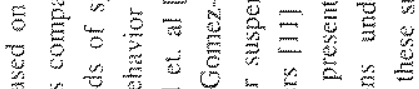

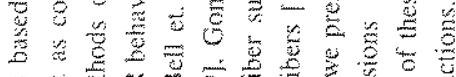

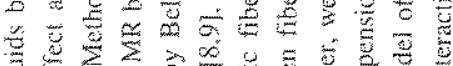

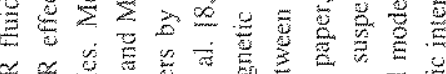

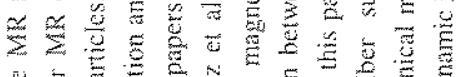

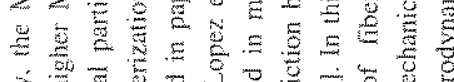

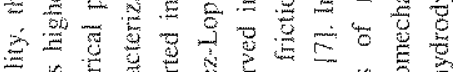

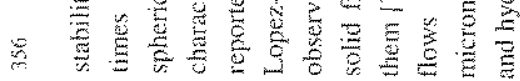

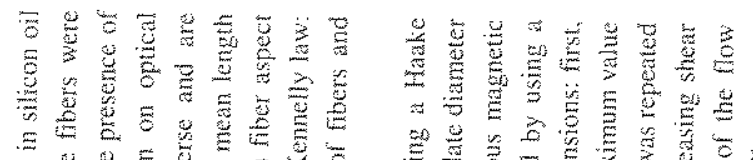

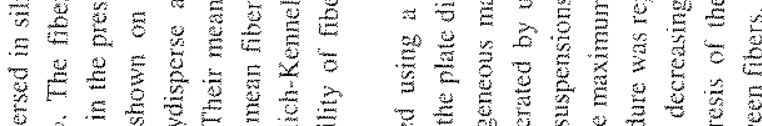

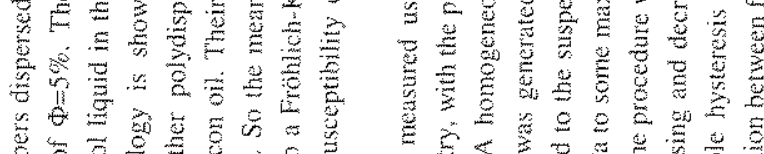

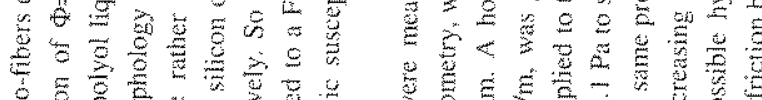

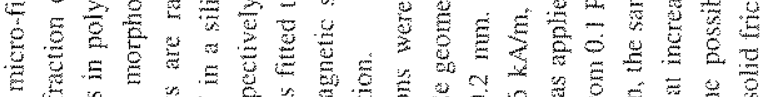

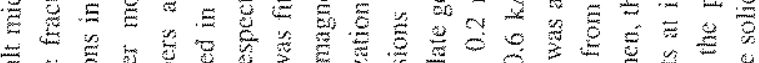

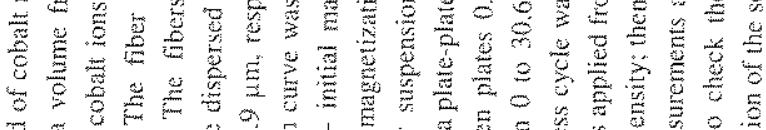

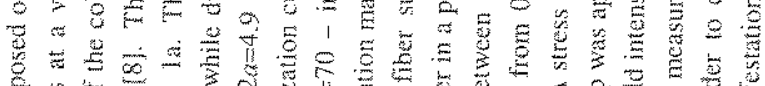

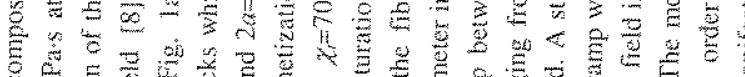

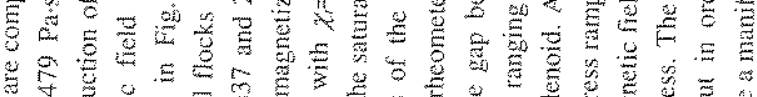

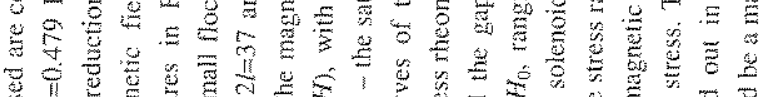

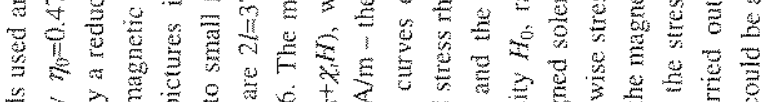

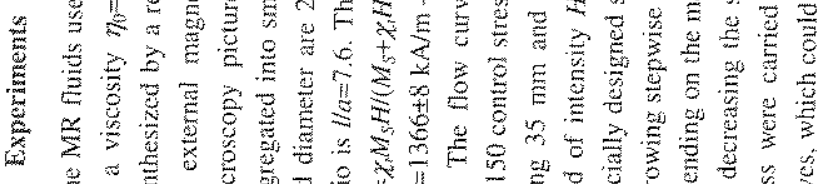

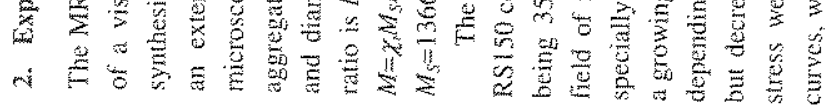




\section{s.}

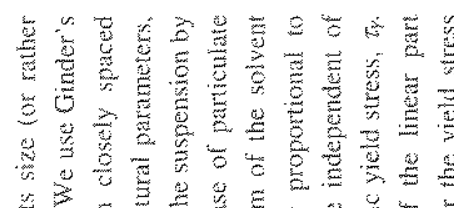

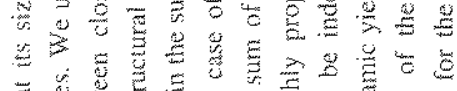

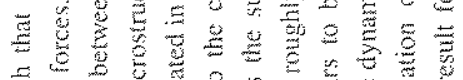

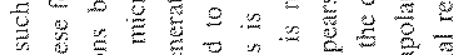

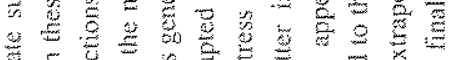

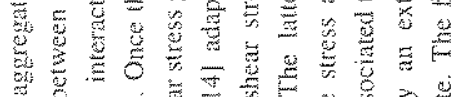

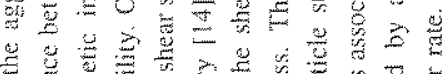

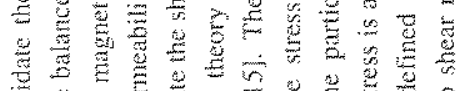

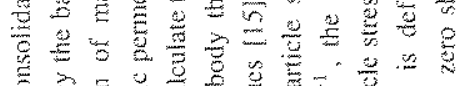

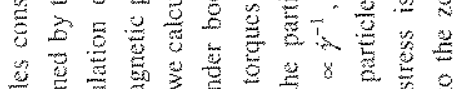

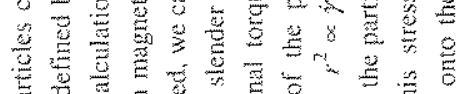

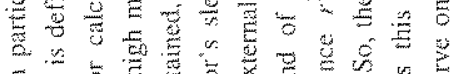

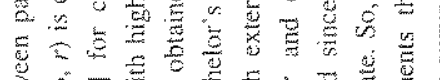

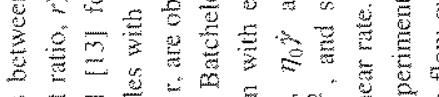

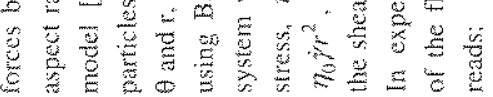

$\Xi$

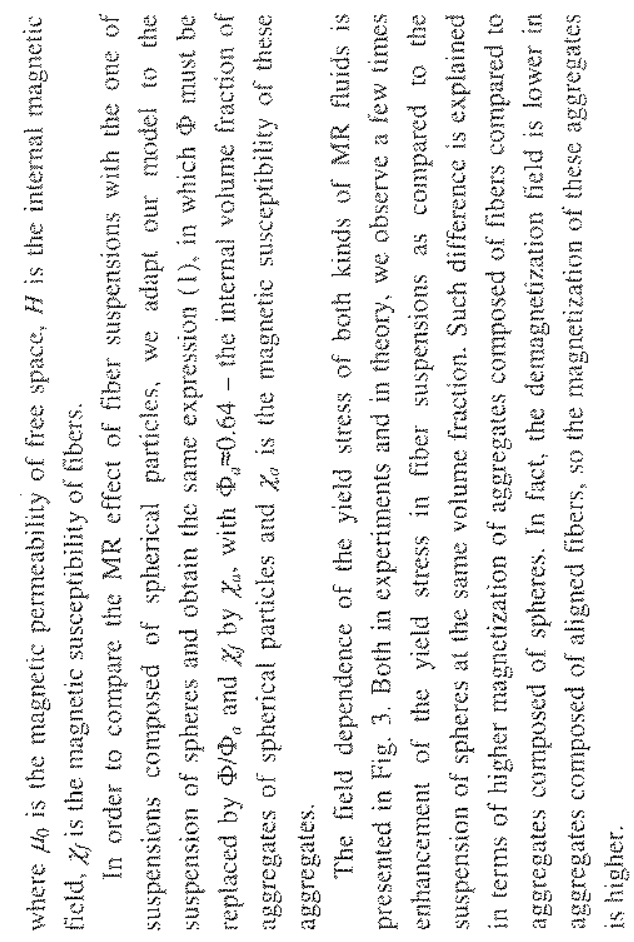

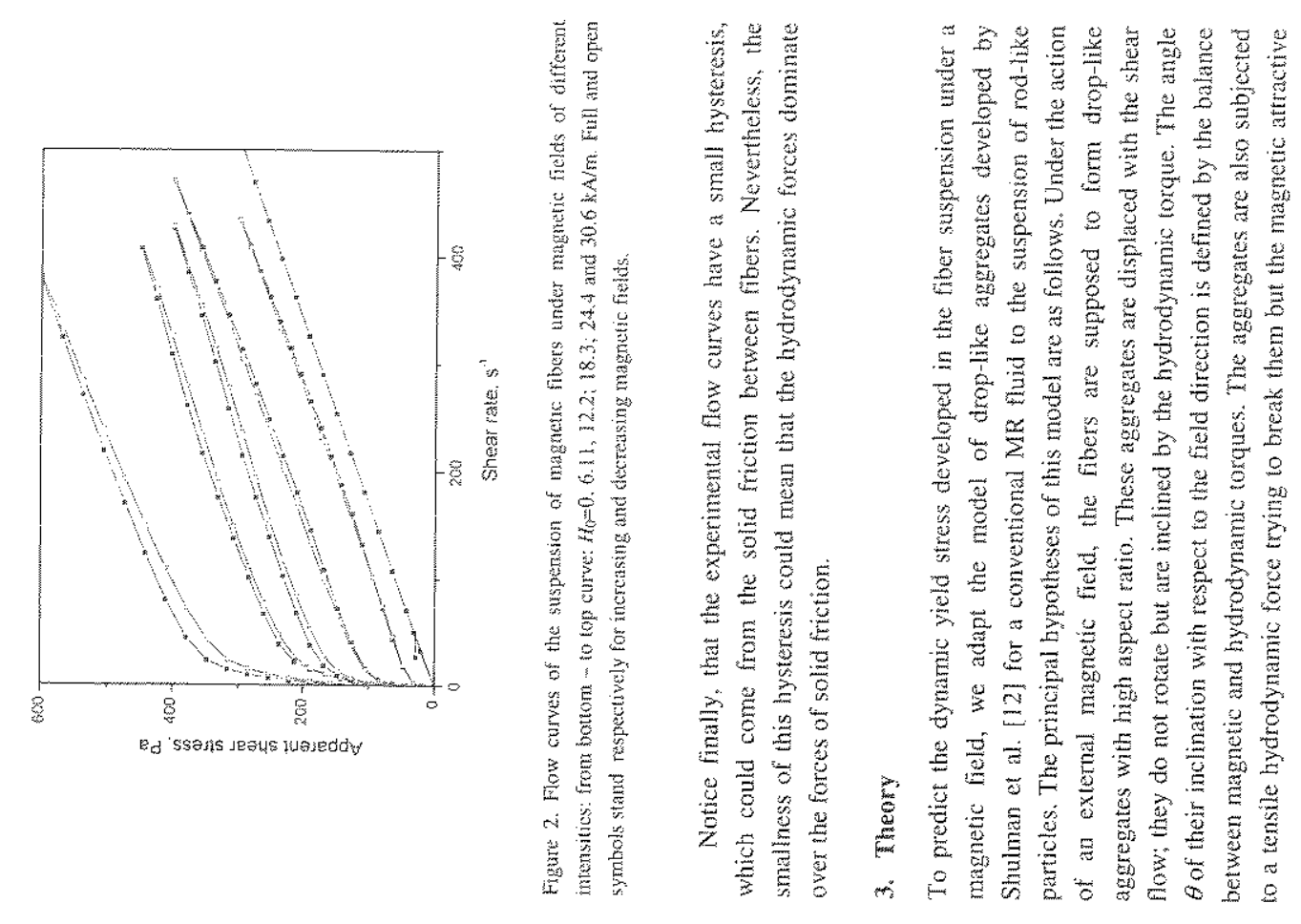




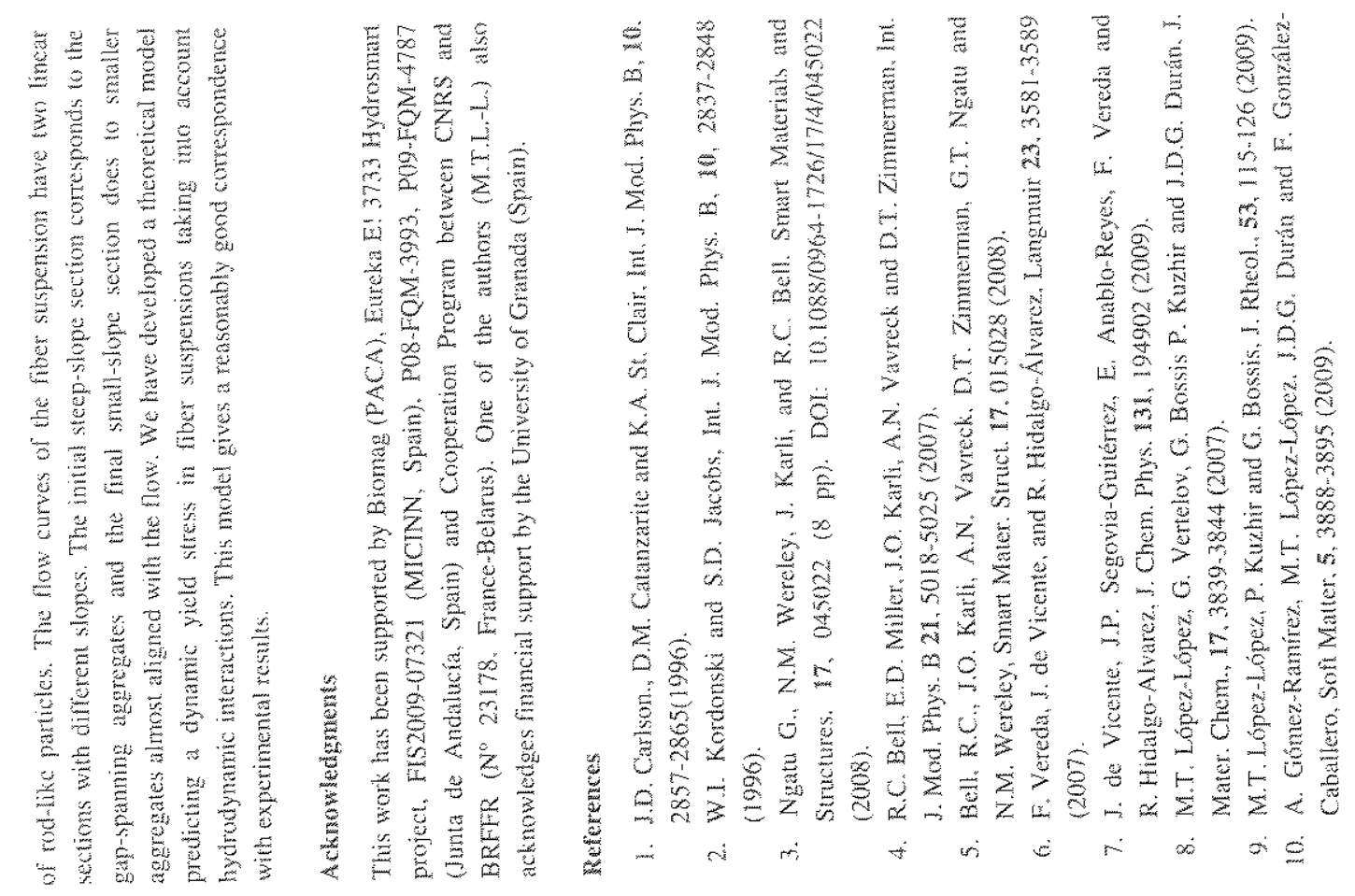

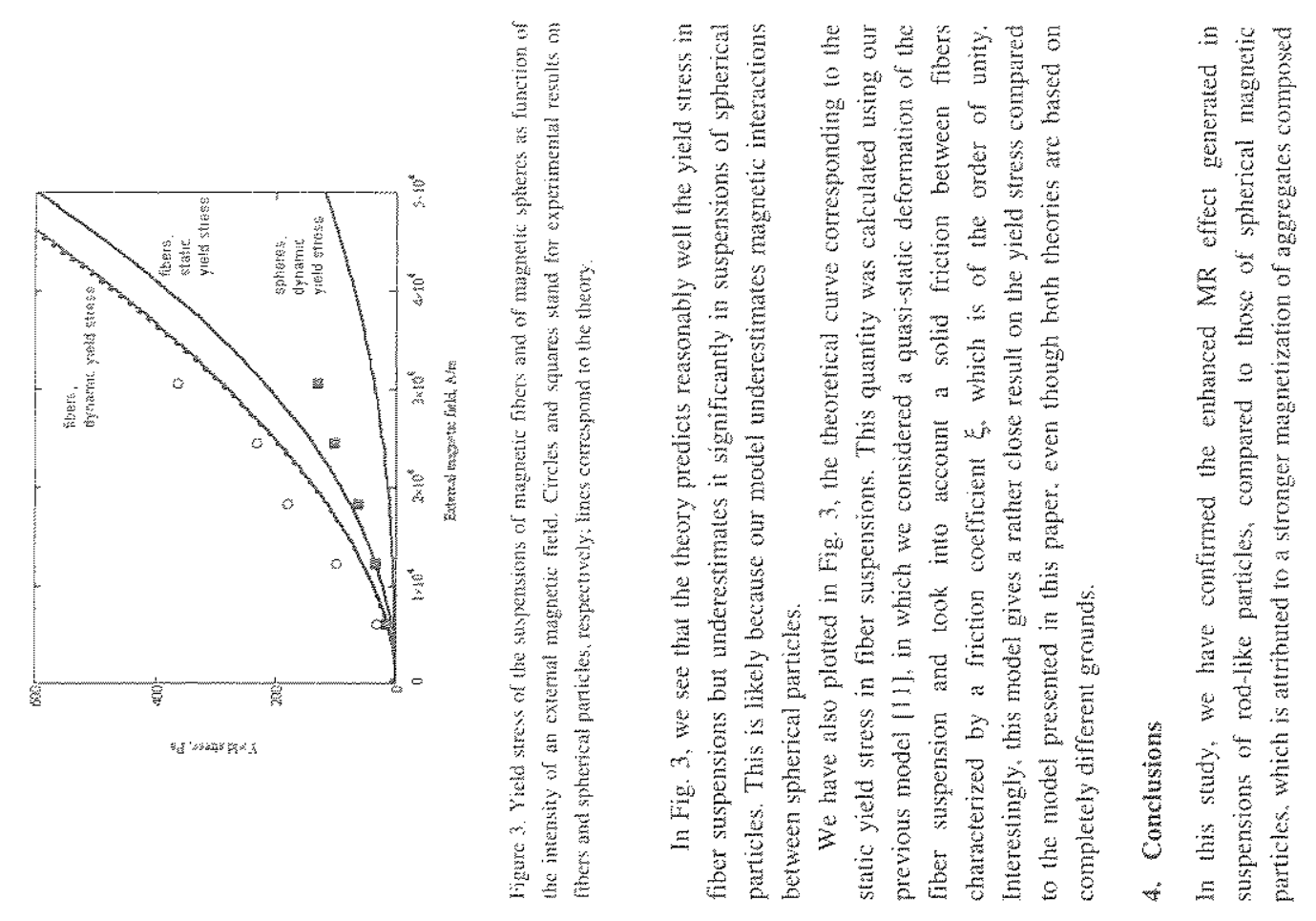

